\title{
Social networks, migration, and care in Tanzania
}

Article

Accepted Version

Evans, R. (2005) Social networks, migration, and care in Tanzania. Journal of Children and Poverty, 11 (2). pp. 111129. ISSN 1079-6126 doi:

https://doi.org/10.1080/10796120500195527 Available at https://centaur.reading.ac.uk/24445/

It is advisable to refer to the publisher's version if you intend to cite from the work. See Guidance on citing.

To link to this article DOI: http://dx.doi.org/10.1080/10796120500195527

Publisher: Taylor \& Francis

All outputs in CentAUR are protected by Intellectual Property Rights law, including copyright law. Copyright and IPR is retained by the creators or other copyright holders. Terms and conditions for use of this material are defined in the End User Agreement.

\section{www.reading.ac.uk/centaur}

\section{CentAUR}

Central Archive at the University of Reading

Reading's research outputs online 


\title{
Social Networks, Migration and Care in Tanzania: Caregivers' and Children's Resilience to Coping with HIV/ AIDS
}

\author{
Ruth M.C. Evans
}

\begin{abstract}
This paper explores the impacts of the HIV/ AIDS epidemic on children and families in northern Tanzania using the concept of social resilience. ${ }^{1}$ The study is based on the findings of child-focused research with street children and children and families from HIV/ AIDS-affected households. ${ }^{2 \&} 3$ I illustrate the coping strategies that children and young people, parents and carers adopt at the household level. In particular, I examine how the burden of care affects different generations of women, and highlight their resilience, together with the importance of social networks and the fluidity of movement between rural and urban areas. The research suggests that migrating to urban areas to seek a living in the informal sector represents a survival strategy adopted by some children and young people orphaned by AIDS when their families and communities are unable or unwilling to support them. I conclude by exploring parents, carers, children and young people's views on the forms of social support that would promote their resilience, and thereby help to mitigate the impacts of the epidemic at the household level.
\end{abstract}

\section{Introduction}

The first cases of HIV / AIDS were reported in Tanzania in 1983, which the Tanzanian government responded to by establishing a National Task Force on AIDS within the Ministry of Health in 1985. Throughout the 1990s, however, government funding of policies to prevent the spread of the epidemic was very limited. In 1999, President Benjamin Mkape declared the HIV / AIDS epidemic a national disaster, and called for joint action from all sectors in drawing up a national strategic policy on HIV / AIDS, which came into effect in 2001. By 2002, it was estimated that 3-400 million US dollars were required annually to halt the spread of the epidemic in Tanzania, yet the 2002 budget allocation represented just 5 per cent of this figure (UNICEF $2^{\text {nd }}$ National Multisectoral AIDS conference 2002).

HIV/ AIDS is having a major impact on already overstretched basic services, such as the health and education sectors. Nearly 2.2 million Tanzanians (6.7 per cent of the total population) and about 1.5 per cent of all children under five years old were living with HIV / AIDS in 2002 and of these about a third required intensive care and support (Mhalu and Lupogo 2002). Only a very small minority of those living with HIV / AIDS who are in need of care and support are able to access any care at all (ibid). Over half of all beds in many hospitals across the country are occupied by people with HIV-related illnesses (UNICEF 2001). The consequences of losing thousands of skilled professionals within the basic services sector to HIV / AIDS, such as teachers, health workers and other care workers, has major ramifications for the future socio-economic development of the country.

Save the Children estimates that in Tanzania, over three million children and young people (aged under 18) had lost their mother, father, or both parents due to all causes in 1999 (Grainger et al. 2001). The majority of the orphans are being cared for by extended family members, reflecting a strong tradition of child fosterage in Africa. This significantly mitigates the impacts of the epidemic. However, many guardians are either too old or too young to meet the orphaned children's material and emotional

(C) Ruth Evans, 2005. Please cite as: Evans, R. (2005) 'Social networks, migration and care in Tanzania: caregivers' and children's resilience in coping with HIV/ AIDS', Journal of Children and Poverty, 11(2): 111-129. 
needs, and many older children leave their adoptive homes and survive in the informal sector on the streets (Karlenza 1998).

There have been many studies conducted on the care and support of children living with HIV / AIDS, most of which focus on children in developed countries (Grainger et al. 2001). However, the needs of children affected through the sickness and death of parents, carers and siblings have not been seen as a priority, even though the number of children affected by the epidemic is far greater than those actually infected (ibid). This has resulted in a lack of child-focused studies on the impacts of the epidemic on children who care for dying parents and relatives, and those who must survive independently on their parents' death. Furthermore, few studies explore the actual experiences of people living with HIV / AIDS and how affected societies themselves perceive the impact of the HIV epidemic (examples of those that do include Anderson and Doyal 2004; Bolton and Wilk 2004). The migration of household members is often used as a coping strategy for the survival of the family, and many children engage in migration to receive care and support (Young and Ansell 2003). However, the literature has not focused on issues of migration, and policy often does not take account of impacts of such migration, and the support needed to enable households to adapt and care for foster children (ibid).

This paper explores the impacts of the HIV/ AIDS epidemic on children and families in Tanzania, using the concept of social resilience. The study is based on findings from child-focused ethnographic social research conducted with street children and children and families from HIV/ AIDS-affected households in Arusha, northern Tanzania during the period 2000-2002. In 2001, the Arusha region had one of the highest infection rates in the country (17.8 per cent) (Ministry of Health 2001). Through a former colleague, I met Elli, a woman who was open about her HIV status and involved in community education programmes about HIV / AIDS. Due to the fear, stigma and ostracism surrounding HIV/ AIDS, I was very fortunate to be introduced to someone who was willing to talk to me openly about their experiences. Elli represented a key gatekeeper in introducing me to other parents living with HIV and families affected by AIDS within her social network who were willing to participate in the research. This was part of a wider child-focused ethnographic study to explore the gendered experiences of street children and children in difficult circumstances in Tanzania (Evans, 2004 ${ }^{\mathrm{b}}$ ). This included semi-structured interviews and drawings with sixteen street children, seven of whom I followed up with unstructured interviews, semi-structured interviews with four parents / carers and interviews and drawings with three children from AIDS-affected households in Arusha, focus groups with 33 street children, 36 school children, and with 17 parents in a community centre, and semi-structured interviews with 13 professionals from non-governmental organisations and the statutory sector in Arusha and Dar es Salaam. This was combined with participant observation on the streets and home visits to 12 of the street children's homes in the region.

In this paper, I draw on individual semi-structured interviews conducted with parents living with HIV, carers, children from AIDS-affected households and street children in Arusha. The research followed ethical guidelines for social research, and the names of all research participants have been changed to protect their anonymity. I illustrate the coping strategies that children and young people, parents and carers are adopting at the household level. In particular, I examine how the burden of care affects different generations of women, and highlight their resilience, together with the importance of social networks and the fluidity of movement between rural and urban areas. I also explore parents, carers, children and young people's own views on

(C) Ruth Evans, 2005. Please cite as: Evans, R. (2005) 'Social networks, migration and care in Tanzania: caregivers' and children's resilience in coping with HIV/ AIDS', Journal of Children and Poverty, 11(2): 111-129. 
the social support needed to build their resilience, which would help to mitigate the impacts of the epidemic at the household level.

\section{Concept of Social Resilience}

The concept of resilience has emerged as a key issue in the field of psychiatric risk research since the 1980s, largely in response to recognition of the need to understand individual differences in people's responses to stress and adversity (Rutter, 1990). As Rutter explained, resilience is the term used to describe the positive pole of individual differences in responses to stress and adversity (ibid). In the field of psychiatric risk research, this has resulted in a shift of emphasis from 'vulnerability to resilience, but also from risk variables to the process of negotiating risk situations' (Rutter 1990:182). This approach centres on understanding the protective factors that help individuals cope in situations of adversity and emphasises the active role taken by individuals in engaging with protective factors. Rutter identifies three characteristics of a person demonstrating resilience: a sense of self-esteem and self-confidence; a sense of self-efficacy (a belief in their capacity to make a difference); and a repertoire of social problem-solving approaches (Rutter 1985).

Children orphaned by AIDS and street children, in particular, have been identified as a category of children "at risk" in recent years. However, the risk discourse is problematic in many ways, since it leads to assumptions of generalised vulnerability, and is often accompanied by "risk anxiety" about groups who are especially vulnerable but who also disturb or violate established social norms (PanterBrick 2002). Researchers have therefore argued that a helpful counterpart to the risk discourse is to focus on the resilience of children who manage to negotiate extremely difficult circumstances. This has led to a shift in thinking about childhood from one that emphasises vulnerability to one that emphasises resilience, and attempts to give a more contextualised understanding of the processes by which children and families negotiate risk situations (Panter-Brick 2002; Rutter 1990). Thus, the shift towards understanding individuals' strengths in coping with adversity within psychiatric risk research has been mirrored in child development, childhood and family research and policy (Gilligan, 1997; Mastem and Coatsworth 1998; Walsh 2002). As Pryor summarises, the broad question addressed by resilience research is "what accounts for why some stay healthy and do well in the face of risk and adversity and others do not?" (Pryor, 2004:1).

Gilligan defines a resilient child as 'one who bounces back having endured adversity or who continues to function reasonably well despite continued exposure to risk' (1997:15). Previous research on child resilience has revealed three broad sets of variables operating as protective factors: attributes of the children themselves; characteristics of their families; and aspects of the wider social context (Masten et al. 1990; Schoon and Parsons, 2002). At the level of the family and community, such protective factors may include the relationship a child has with a parent or other significant adult in their life and with their siblings, a supportive extended family network, their friendships with their peers, positive school experiences, opportunities to engage in social life, religious faith and membership of a faith community (Masten et al. 1990; Gilligan 2001). Some of these protective factors are common to children and adults, whereas others are specific to childhood resilience, such as a child's attachment to a significant adult and positive school experiences. However, such protective factors are context-specific and may vary cross-culturally (Schoon and Parsons 2002). Empirical research has yet to confirm the relevance of the concept of

(C) Ruth Evans, 2005. Please cite as: Evans, R. (2005) 'Social networks, migration and care in Tanzania: caregivers' and children's resilience in coping with HIV/ AIDS', Journal of Children and Poverty, 11(2): 111-129. 
resilience for children in adversity in countries of the South, since most of the work on resilience is concerned with industrialised countries (Panter-Brick 2004; 2002).

As Rutter suggests resilience "cannot be seen as a fixed attribute of the individual. If circumstances change, the risk alters" (Rutter 1990, 184). Bloom (1996) argues that social resilience resides more in the contexts, systems or relationships to which a person belongs than in the individual as such. Luthar (1993) suggests that is more helpful to think of resilience in different domains of functioning, rather than as a universal quality of the individual. Thus resilience may be evident in one domain of functioning, for example, school or the workplace, yet not in another, for example, the family (Gilligan, 2001). It does not follow that the quality of resilience is displayed to the same degree in each domain (ibid). Thus, children and adults may be more or less resilient within different domains, and at different points in their lives, depending on the interaction and accumulation of individual and environmental factors (Howard et al. 1999).

Rutter (1990) argues that vulnerability and protection are 'the negative and positive poles of the same concept, not different concepts' (1990:185). He also suggests that 'many vulnerability or protective processes concern key turning points in people's lives rather than long-standing attributes or experiences', which then determine the direction of trajectory for the years that follow (1990:187). He argues that attention should be paid to 'the mechanisms operating at key turning points in people's lives, when a risk trajectory may be redirected onto a more adaptive path' (1990:210). In child development research, researchers have drawn on the idea of developmental pathways or trajectories along which children progress as they grow up (Bowlby, 1988). Rutter has argued that 'from the perspective of the child, new and positive experiences that present opportunities can provide beneficial 'turning-point' effects which, although not necessarily preventative in themselves, can be helpful if they neutralise some risk factors' (Rutter 1999). As Gilligan suggests, within any system, small changes can have 'an important wider ripple effect generating momentum possibly for a virtuous spiral of change and development' (Gilligan, 2000:38). He suggests that 'one favourable experience may be a turning point in a child's or young person's trajectory of development' (Gilligan, 2000:39).

In this paper, I explore the relevance of the framework of resilience, vulnerability and protective factors to understanding the processes by which children and families negotiate the impacts of the HIV / AIDS epidemic. I focus on the coping strategies individuals (both adults and children) adopt within the domains of the family and community, such as making best use of limited resources, engaging in migration and developing effective social networks.

\section{Chronic Poverty and Gendered Care Responsibilities}

Research with street children in Tanzania has described the ways that poverty both constrains families' abilities to provide for their children, as well as placing great pressure on adult-child relationships within the family (Evans 2004 ${ }^{\mathrm{a}}$ ). Due to economic pressures, and greater conflicts of interest, accompanied by social marginalisation, it has been suggested that the marriages and households of poor families may be more unstable than those of the rich in some societies (Lockwood 1997). Interviews with children and families affected by HIV / AIDS in Arusha illustrate these processes of extreme poverty and the social marginalisation which results from, and reinforces poverty, as structures of households change to adapt to the epidemic. These processes represent risk and vulnerability factors at the level of

(C) Ruth Evans, 2005. Please cite as: Evans, R. (2005) 'Social networks, migration and care in Tanzania: caregivers' and children's resilience in coping with HIV/ AIDS', Journal of Children and Poverty, 11(2): 111-129. 
the family and social environment, although they impact most on the survivors of AIDS-affected households, usually children and elderly grandparents (Barnett 1998).

Research in Uganda found that children being cared for by grandparents were particularly vulnerable to malnutrition and infectious diseases, since food production was low and medical care was unaffordable (Barnett and Blaikie 1992). Children being cared for by single female grandparents, particularly in rural areas, were even more vulnerable, because women generally have lower incomes and depend more on friendship-based goodwill (ibid). A study in Tanzania and Zambia found that an estimated 80 per cent of foster parents are grandmothers (Caldwell 1997). In addition, children are likely to experience further trauma when their elderly carers eventually die. The inversion of the tradition of grandparents being cared for by younger members of the family puts a severe strain on the household economy as well as family relationships (Grainger et al. 2001).

The research with children and parents and carers in Arusha showed how the burden of care affects different generations of women, emphasising the point that women and girls often bear the greatest costs of adult ill-health and death, "primarily because of the significant opportunity costs to them of their traditional roles as carers and nurturers of the ill or dying" (Godwin 1998, 3). Children and elderly grandparents in families participating in the study who had previously been supported by fairly well-educated parents, had seen a dramatic decline in the household economy as each parent in turn succumbed to ill-health and eventually death, leaving the survivors vulnerable to chronic poverty. The strain of poverty and the domestic burden of caring for four children following the death of both parents was painfully apparent in an interview with an elderly grandmother. The grandmother was about 80 years old, and relied on buying and then selling bananas at the roadside near the house. She made about 200 Tanzanian Shillings a day (roughly equivalent to 14 pence), which was not enough to feed the family. They had some relatives who lived in another part of the town, who did not offer any support:

G: My story, I've got problems, because the deceased doesn't have any brothers, there's no brothers, so the children can't go to the brothers of the deceased, there's no brothers. The deceased died, that's all, and left me with the children. [...]

RE: So you look after the children?

G: $\quad$ Yes, just me. I just stay here.

RE: Do you grow food?

G: Ah! No, food is a problem, even the house, I don't have one for the children, we just sleep. We don't even have a house.

RE: Really?

G: $\quad$ That one, if it rains, it rains on us. (Grandmother, 12/12/02) $3 \& 4$

This suggests that the grandmother lacked potential protective factors such as support from the extended family or social networks with neighbours and friends, which would help to mitigate the risks of the HIV/ AIDS epidemic. The family was therefore particularly vulnerable to a trajectory of chronic poverty and potential disintegration of the household.

One of the orphaned children interviewed from this household, Doreen, was 12 years old and had started school later than her brothers. This was due to her domestic duties that involved helping to care for her parents through the last stages of their illness, as well as caring for the rest of the household. She was studying in the

(C) Ruth Evans, 2005. Please cite as: Evans, R. (2005) 'Social networks, migration and care in Tanzania: caregivers' and children's resilience in coping with HIV/ AIDS', Journal of Children and Poverty, 11(2): 111-129. 
second year of primary school and had been sent home on previous occasions for wearing torn school uniform and not having any shoes. Thus, her prospects for continuing her education at school seemed limited. Doreen's care responsibilities were linked to cultural expectations of gender roles, whereby girls are expected to take on a greater proportion of the household tasks than their brothers. This can restrict the amount of time available to girls for recreation and study, which has a proven adverse effect on girls' educational performance (Bendera 1999; Kuleana 1999). The grandmother told of how Doreen's older brother (aged 18) had dropped out of primary school, where he had been studying in Standard 5, and spent less and less time at home, probably seeking economic independence through employment. Doreen's responses to questions about who she approached in times of need reveal the importance of her immediate relatives for emotional support, but also demonstrate the household's vulnerability, expressed through a lack of access to health care:

RE: $\quad$ At home, who would you go to/ where would you go if you're ill?

D: $\quad$ There's nothing. Nowhere.

Grandmother: Just God. [...] Even if I'm ill, that's how it is.[...]

RE: $\quad$ And if you feel sad, who would you go to?

D: $\quad$ To grandma.

RE: $\quad$ And if you want some advice, where would you go to?

D: $\quad$ To my older brother.

RE: $\quad$ And if you get bad news, where do you go?

D: $\quad$ I tell grandma.

RE: $\quad$ When do you feel safest? Or you feel happy?

D: $\quad$ There's none. [...]

Re: When do you feel lonely?

D: $\quad$ If I get ill. (Doreen, aged 12, 12/12/02). ${ }^{3 \& 4}$

However, Doreen played a vital role in helping her grandmother with the household chores and caring for her younger brothers, mentioning this as a positive aspect of home:

RE: What do you like doing at home?

D: $\quad$ Just any work at home. [...] I wash the dishes, cook, sweeping. [...]

RE: $\quad$ Tell me the three most important things for your future.

D: $\quad$ Education, if I get work...I'll help grandmother and my younger brothers.

RE: When you're older, what kind of work would you like to do? What do you want to be?

D: $\quad$ I'd like to be a teacher. (Doreen, 12/12/02) ${ }^{3 \& 4}$

Doreen had positive aspirations for the future and a sense of responsibility in terms of caring for her relatives. Some researchers have suggested that although children who care for other household members might be considered particularly at risk since they may give emotional as well as practical support and may have to make sacrifices in terms of their education, children can express resilience through taking on caring responsibilities for their immediate relatives (Woodhead et al. 2003). While Doreen's help with domestic chores may be a way that she seeks to keep her family together and support her grandmother, and she is thus expressing her agency in coping with the impacts of the epidemic, it is unclear how this might protect her from a trajectory of

(C) Ruth Evans, 2005. Please cite as: Evans, R. (2005) 'Social networks, migration and care in Tanzania: caregivers' and children's resilience in coping with HIV/ AIDS', Journal of Children and Poverty, 11(2): 111-129. 
chronic poverty and low educational outcomes in later life. Thus, a gender perspective and gaining an understanding of the social structural inequalities operating at the household level appears more appropriate than the resilience, vulnerability and protection framework in this instance.

\section{Female-headed Households and Social Networks}

In many sub-Saharan African countries, the stigma of HIV / AIDS coupled with high levels of poverty tends to lead to children may be denied access to schooling and health care. Their rights to inheritance and property may also be denied, particularly in the case of girls (UNICEF 1999 ${ }^{\text {b }}$ Barnett and Blaikie 1992). The rights of children are closely linked to those of the surviving parent. Thus, in Tanzania, as in other African countries, the customary laws which deny widows the right to inherit their deceased husband's land, can have devastating consequences for children after their father's death (UNICEF 1999 ${ }^{\mathrm{b}}$ ). Women who live with male partners and have children who are born outside of marriage are particularly vulnerable to poverty after their partner's death, as the story of Theresa, a mother who had been living with HIV for seven years, illustrates:

T: $\quad$ When my husband died, his relatives came and took all the furniture and household goods. Here, for a Tanzanian woman with children, it's not until you get married that you're given any control, but we weren't married, they took all the furniture, I was left with my children.

RE: They took everything?

T: $\quad$ Everything in the house. I started a life of sleeping on the floor and helping out at my neighbour's houses.

RE: It was in 1998?

T: $\quad$ Yes, 1998. I started a life of problems and now, I've just got used to it. So for the children, it's just me who looks after them and provides for their education on my own, no one else helps me.

RE: Do you work?

T: I don't have any work. I hope to set up a small business but I don't have any capital. (Theresa, 12/12/02) ${ }^{3 \& 4}$

This illustrates the vulnerable situation of female-headed households and the children within them, as well as the importance of women's social networks at times of crisis, in this case, the support of neighbours and friends. A study conducted in Tanzania found that women were heads of nearly 40 per cent of orphan households, compared with 15 per cent of non-orphan households (Urassa et al. 1997). Thus, HIV / AIDS is contributing to a rise in female-headed households which are generally more impoverished than male-headed households, especially in rural areas (ibid).

The story of another family highlighted the resilience of different generations of women in coping with the impacts of the epidemic at the household level. Elli had been living with HIV for over seven years, and she lived with Stephan, aged 13 years, in Arusha, where she played an active role in AIDS awareness education in the community. Stephan described how the discovery of their HIV status had caused the break up of his parents' marriage, and his father's rejection of him and his siblings. This illustrates the idea discussed by Lockwood, that in African societies it is social, rather than biological paternity which is important, and that people may choose courses of action to emphasise or de-emphasise particular relationships at particular

(C) Ruth Evans, 2005. Please cite as: Evans, R. (2005) 'Social networks, migration and care in Tanzania: caregivers' and children's resilience in coping with HIV/ AIDS', Journal of Children and Poverty, 11(2): 111-129. 
times (Lockwood 1997). This can result in the rejection and marginalisation of women and their children. Elli's mother cared for Elli's two other sons, one of whom (aged 7) was infected with HIV in their home village several hundreds of kilometres away:

RE: Have your sons lived there [with their grandmother] for a long time?

E: Two years now.

RE: You decided they...?

E: $\quad$ They should live there because I get ill every so often and it's hard for me to provide for them. The youngest one is infected and gets ill too.

RE: Does he know?

E: No, we haven't told him, but the older ones know. I'm afraid to tell him.

RE: And your mother is still quite fit?

E: $\quad$ She's still quite fit, but I have to help her, I send her money.

RE: Does she do agricultural work?

E: Yes.

RE: And you go to see them?

E: When I can, the last time I went was May last year, if I get the bus fare, I'll go. It's a long way.

RE: Are they there on their own with your mother, or are there other relatives there?

E: No, they're just there with their grandmother. Their grandfather died. (Elli, $12 / 12 / 02)^{3 \& 4}$

This shows that female members of the extended family, especially grandmothers, represent a vital source of support and a coping mechanism for women living with HIV / AIDS, whose ability to care for their children was being reduced due to their illness. This suggests therefore that women's social networks could represent important protective factors at the level of the family and community.

\section{Coping Strategies of Child-headed Households}

Since the late 1980s, the emergence of child-headed households in some sub-Saharan African countries has been linked to the HIV / AIDS epidemic. Foster et al. (1997) suggest that although the children themselves may prefer to live in a child-headed household, members of such households typically suffer from a lack of supervision and care, poor nutrition, declining health status, educational failure, exploitation and abuse by adults, early or delayed marriage, discrimination, and disruption of childhood and adolescence. However, the study shows that children and young people in child-headed households demonstrate resilience in developing a range of coping strategies to meet their basic needs.

One of the interviewees, Charles, was 17 years old and studying in the second year of Secondary school. He lived with his 20 year old sister and 13 year old brother in the house left to them by their parents, who had recently died of AIDS. He told me that all his uncles on his mother's and father's sides of the family had died of AIDS, and his grandparents had also died, so their only surviving relative was an uncle who was disabled and unable to care for them. Coping strategies adopted by the children following the death of their parents included doing casual agricultural labour after school to earn a limited amount of money to support the household, reducing the 
household's food consumption and seeking financial support from adults to enable Charles and his younger brother to continue at school.

A study in Uganda suggested that the likely success of child-headed households depended on the age and gender of the eldest sibling, with teenage girls identified as more able to ensure the household's survival due to their early socialisation in domestic work (Barnett and Blaikie 1992). Safeguarding orphans' rights to inherit their deceased parents' tenure of the farm was also found to be an important issue for orphans (ibid). In the case of members of a child-headed household interviewed in Arusha, Charles, together with his siblings, seemed to stand a good chance of surviving as a household since he and his older sister were in their older teenage years when they were orphaned, had a good level of education, and there appeared to be no danger of being disinherited from their parents' small house. These could be considered protective factors, which help to mitigate the risks at the individual and household level. The older sister's lack of employment or capital to start a small business and the two brothers' dependence on charity to enable them to continue at school, however, represented vulnerability factors, and the household was at risk of disintegrating if the older siblings left in search of employment or marriage.

Charles was asked about his coping strategies, and especially who he would approach for guidance and emotional support. His account suggested that orphaned children were forced to become self-reliant early on and meet their own survival and emotional needs themselves. Charles took on agricultural labour in order to earn money for food. However, this meant that he no longer had time to play football with his friends. He felt that adults were no longer an option for emotional support due to their own illness:

RE: If you feel sad, who do you go to?

C: If I'm sad, I like to work to get rid of my thoughts. [...]

RE: At home, who do you go to if you get bad news?

C: $\quad$ Bad news? What like?

RE: $\quad$ Say, that you heard a relative has died?

C: $\quad$ It's a good question. [..] You can't go to grown ups because their illness just gets worse. I would start with my sister. [...]

RE: When do you feel happiest?

C: $\quad$ The days when I don't think about things, I feel happy. (Charles, aged 17, $12 / 12 / 02)^{3 \& 4}$

This shows the importance of sibling relationships as a source of emotional support and advice for orphaned children. This may represent a protective factor within the domain of the family, which enables children from child-headed households to better cope with their situation.

\section{Children and Young People's Migration Strategies}

According to Karlenza, Director of CREDO, a Tanzanian NGO working with AIDS survivors (orphans, the elderly and children in distress), "Many orphaned children are traumatised, poorly socialised, lack emotional support, receive little education, and are poorly equipped for adult life. Many older children leave their adoptive homes and seek a better life on the streets" (Karlenza 1998, 5). The orphaned children participating in the study were clearly at risk of turning to the informal sector on the streets for survival when faced with a lack of financial and emotional support from

(C) Ruth Evans, 2005. Please cite as: Evans, R. (2005) 'Social networks, migration and care in Tanzania: caregivers' and children's resilience in coping with HIV/ AIDS', Journal of Children and Poverty, 11(2): 111-129. 
their communities and with no opportunity to continue with their education or earn a livelihood. One of the parents living with HIV identified the harassment and lack of support for orphans as being a key factor in orphaned children's move to the street: "Orphans are abused, they don't have any support at all, that's why you see that they become street children. The government should be close to them" (Theresa, $12 / 12 / 02) .{ }^{3 \& 4}$

Indeed, the experiences of two of the street children participating in the study revealed that migrating to urban areas and attempting to sustain livelihoods on the street represents a survival strategy adopted by some children orphaned by AIDS when their families and communities are unable or unwilling to support them. The experiences of Simon, a 14 year old boy living on the streets at the time of the interview, illustrates the rejection and stigma children may face following the death of their parents from AIDS-related illnesses:

I used to live in Babati with both my parents. My mama became ill with pneumonia and died in Babati. We moved to Arusha with my brother. Then my brother went away to Nairobi, and my sister got married and went back to Babati. Then my father too became ill, with TB, his lungs were rotten and he died. Then my (paternal) uncle treated us badly, I mean, we didn't have anywhere to stay. We had to leave. We left, the two of us, we went to a woman" s house. We worked for her in her house but she refused to pay us. We left and my brother went to Morogoro and I came here. [...] At home, there were problems, but not that we had to go without food or school fees. But when my parents died, then we went without food a lot and school fees (Simon, aged 14, living on the street at time of interview, 11/6/00). ${ }^{3,4 \& 5}$

Simon's account shows how the rights of children from some AIDS-affected households are denied, with the extended family effectively disowning them following the death of their parents. His narrative also shows the multiple migrations that different members of the household may engage in to cope with the impacts of HIV/ AIDS.

The narrative of Amina, a 14 year old girl living on the streets at the time of the interview, illustrates how HIV/ AIDS affects different generations of women. Following the death of her younger child, Amina's mother migrated from a rural area to Dar es Salaam to search for work. Amina and her elderly grandmother, already facing chronic poverty, nursed and cared for Amina's mother when she returned to their home in the village suffering from AIDS-related illnesses. Her elderly grandmother was no longer able to provide for Amina following her mother's death, and Amina experienced rejection and harassment from her extended family, expressed through exploitation as a domestic servant at her step-brother's home:

A: When my younger brother died, my mama left and went to Dar es Salaam, and my father left for Mwanza. And me, I stayed with my grandmother. [...] When mama came back, she was ill and I helped with the work at home, fetching water, for example, cooking, boiling water for mama, or relieving the pain with a cold press in the places she hurt. When she made it to the third month, yes, in the third month she died.

RE: I'm very sorry. What illness was it?

A: I don't know, she was just ill, with malaria, coughing, being sick, passing diarrhoea and blood [AIDS-related illnesses]. Once she was buried by my

(C) Ruth Evans, 2005. Please cite as: Evans, R. (2005) 'Social networks, migration and care in Tanzania: caregivers' and children's resilience in coping with HIV/ AIDS', Journal of Children and Poverty, 11(2): 111-129. 
relatives, they hated me, because mama had died and there was no one to look after me. I had to go to my brother's and I lived there for about three months with my father's relatives. I was harassed as I had been before and I said to myself, "I can't be harassed like this again", I'll have to start out on the streets. (Amina, 09/06/00). ${ }^{3,4 \& 5}$

Amina's narrative illustrates the important role that children, particularly girls, can play in caring for and nursing their dying parents or relatives. The story also demonstrates the migration strategies members of the household adopt to cope with the impacts of the epidemic, indicating a fluidity of movement between rural and urban areas. The AIDS stigma, which is often transferred from parents to children, combined with the tradition of child fosterage within the extended family, can leave orphans vulnerable to exploitation as domestic servants, where they may be subjected to harassment and physical and emotional abuse. Amina's response to the abuse was to migrate to an urban area and engage in livelihood strategies in the street. This demonstrates the complex ways children and young people exert their agency in coping with adversity. However, this does not correspond to the literature on resilience, as moving to the street environment, characterised by a high level of risk, is not considered a 'successful outcome' from a child development perspective.

Research with street children in Tanzania has highlighted young people's resilience in negotiating for their basic needs, earning money, and developing effective social networks amongst their peers and adults in the street environment (Evans $2004^{\mathrm{b}}$ ). However, living independently on the street also places young people at particular risk of becoming infected with HIV themselves. The low levels of condom use in sexual relationships in Tanzania, as in many other countries, is heightened by a culture of risk-taking within the street environment. The study also suggested that street children are particularly vulnerable to sexual abuse, exploitation, and survival sex with adults and their peers in exchange for food, shelter, or protection. This is combined with a lack of access to health care or sexual health information aimed at young people within the street environment (Evans 2002).

It is likely that many of the street children living at the street children centre where I worked during the fieldwork period who had been orphaned had lost parents and carers due to HIV / AIDS, although the children themselves rarely cited this as the cause of death. However, as Karlenza (1998) notes, experience from other countries suggests that it is important not to label children orphaned by AIDS as "AIDS orphans", or single them out for development assistance, because this may stigmatise them and other children in poor communities suffer many of the same disadvantages. Indeed, my research shows that children whom UNICEF defines as "social" orphans (whose parents are not available to care for them) are just as vulnerable as "biological" orphans (one or both parents have died). Parents in a discussion group conducted in Arusha as part of the UNICEF study "Children in Need of Special Protection Measures: a Tanzanian Study" (UNICEF 1999") suggested an all-inclusive definition: "An orphan is a person [child] who does not have people to take care of him or her, or one who has lost his/her father or mother, or whose father and mother are unknown" (ibid, 116). Most of the street children participating in the study were included in this definition of an orphan.

\section{Policy Implications}

(C) Ruth Evans, 2005. Please cite as: Evans, R. (2005) 'Social networks, migration and care in Tanzania: caregivers' and children's resilience in coping with HIV/ AIDS', Journal of Children and Poverty, 11(2): 111-129. 
Taking a social resilience perspective, the implications for development interventions working with children and young people, parents and carers affected by HIV / AIDS are to try to build on positive protective factors in people's lives, and support their social networks and coping strategies. Interviews with parents living with HIV / AIDS, carers and children and young people from HIV/ AIDS affected households in Arusha seem to support the approach of starting from people's own coping strategies and recognising their agency. Parents living with HIV/ AIDS expressed their disappointment in the government's lack of commitment to involving people living with HIV / AIDS in community-based education programmes, and the lack of appropriate care, support and access to basic services for people affected by HIV / AIDS. Women living with HIV highlighted the need for governmental leadership towards changing attitudes towards people living with HIV / AIDS, to recognise their capacity to contribute to society and actively involve them in shaping responses to the HIV / AIDS epidemic. One of the interviewees, Theresa, a mother living with HIV for the past seven years, commented:

T: $\quad$ The government should educate the citizens not to treat people with AIDS like us badly, so that they get enough education.

RE: What can government, community, religious organisations, various NGOs do to help people who are infected with AIDS?

T: $\quad$ They can help us as they help other people who don't have any money, because if you have AIDS, it's guaranteed that you'll be ill for a long time and you'll end up selling everything that you have at home. So the government could help us even with money. Because firstly the government needs to see us not as sick people, to give people work.

RE: Is it very difficult to get work?

T: It's very difficult to get work, the government refuses. There's other people like us, who are healthy like us too, what is needed is for us to get work, or those who have got worse to put an amount aside to take to them. There are some who just sleep on their bed all the time, they can't look after themselves, it's us, people who are infected, who go and do day labour there, we take nurses there to their bed. What is needed is for the government to be close to us (Theresa, Arusha, 12/12/02). ${ }^{3 \& 4}$

This shows the key role that government could potentially play in supporting the active involvement of people living with HIV / AIDS in community-based education programmes in order to raise awareness and help to combat the stigma and discrimination experienced by other people affected by the disease. It also highlights the need to protect the rights of people living with HIV / AIDS to employment and livelihood strategies, provide adequate support and care for those living with AIDS, and recognise and support the social networks that people living with HIV / AIDS develop to support each other, through counselling and caring for each other, within the context of poor medical and health care infrastructure.

The parents living with HIV who were interviewed emphasised the importance of society accepting and being open about the disease, not only to halt the spread of the epidemic, but also to improve the physical and mental well-being of people living with HIV. Benefits that interviewees experienced since they became open about their HIV status included being able to access free healthcare (provided by some nongovernmental organisations), increased awareness about the importance of nutritional foods to enhance their physical resistance to the disease, supporting and counselling

(C) Ruth Evans, 2005. Please cite as: Evans, R. (2005) 'Social networks, migration and care in Tanzania: caregivers' and children's resilience in coping with HIV/ AIDS', Journal of Children and Poverty, 11(2): 111-129. 
each other and becoming involved in self-help groups within community-based organisations and NGOs, which enabled them to develop social networks with others living positively with HIV. They commented that social networks and support gave them hope and helped to combat their sense of isolation and stigmatisation. This suggests that social networks and support within the social environment could represent important protective factors for parents living with HIV / AIDS.

Parents living with HIV also emphasised their concern for the well-being of their children in the future since there was limited financial, educational, emotional support available or access to health care for orphans from government or NGO sector. This indicates that, as well as fostering protective factors within the family and social environment, there is a need to address the basic needs of children and families affected by HIV / AIDS. Agencies' responses towards orphans and other vulnerable children to date have consisted of several community-based organisations, religious agencies and other NGOs spearheading initiatives for orphans and families most in need. Kateregga notes that, "although many of these initiatives are urbanbased and usually on a small-scale, their collective response so far provides the most reliable alternative safety nets for children, besides their extended families" (1999, 17). It is generally recognised that compared to institutionalisation, community-based care for orphans is cost-effective, builds on local communities' own coping strategies and, because it keeps children in a familiar social, cultural and ethnic environment, reduces their distress (UNICEF $1999^{\mathrm{b}}$ ). However, due to limited resources, government funding in Tanzania has been mainly targeted at orphanage institutions for a small minority of orphaned children experiencing hardship, under the Social Welfare department (ibid). Kateregga notes that by 1997, some 2,500 children were being cared for in 45 such institutions, and experience has shown that it has been difficult to find foster parents for them, although the policy is that children should be moved into a family setting by the age of three years (ibid).

Charles, a 17 year old orphan living in a child-headed household, identified the priorities for his future as: "Education, a good house which will last a long time, to get some capital which would help to develop our livelihood, to do business" (Charles, 12/12/02). This response indicates the relevance of the social resilience approach to thinking about childhood if this is combined with social support mechanisms to meet basic needs.

\section{Conclusion}

This paper has provided some insight into some of the processes by which women, children, and young people negotiate risks and cope with the impacts of the HIV/ AIDS epidemic. The research shows that the epidemic is exacerbating the chronic poverty, social marginalisation and gender inequalities experienced by poor households in Tanzania. Female-headed and child-headed households are particularly vulnerable to extreme poverty and insecurity, resulting in a lack of access to health care, education, property, livelihood and food security. The stigma surrounding HIV/ AIDS still appears to be pervasive in northern Tanzania, and results in discrimination and ostracism within and outside the extended family. The research highlighted how the burden of care falls predominantly on different generations of women. However, the study also demonstrates the ways women, children and young people express resilience, and shows that women's social networks were crucial to the survival of female-headed households. These networks were characterised by a fluidity of

(C) Ruth Evans, 2005. Please cite as: Evans, R. (2005) 'Social networks, migration and care in Tanzania: caregivers' and children's resilience in coping with HIV/ AIDS', Journal of Children and Poverty, 11(2): 111-129. 
movement between rural and urban areas, and enabled women to cope with caring for children and sick and dying relatives.

Children from AIDS-affected households are considered a particularly "at risk" group since they must cope with the AIDS stigma, the prolonged terminal illness of one or both parents, siblings and other relatives, bereavement and meeting their own survival needs as orphans. As would be expected, this has a detrimental impact on children's psychosocial health and well-being at the level of the household and community and places children and young people from AIDS affected households at risk of trajectories of social exclusion. However, the study has shown that children and young people express their agency and resilience through taking on caring responsibilities for their immediate relatives, and meeting the survival needs of the household. Furthermore, children and young people's relationships with siblings and other surviving members of the household are an important source of emotional support, which may represent a protective factor in mitigating individuals' vulnerability.

The study also demonstrates that seeking a living independently in urban areas represents a migration strategy adopted by some children and young people who are ostracised by their extended family following the death of their parent(s). Children and young people show considerable resilience in negotiating to meet their survival needs, developing social networks and living independently with their peers on the street. However, young people are at particular risk of HIV infection themselves within the street environment.

Whilst children and families affected by HIV / AIDS may express resilience through engaging with protective factors such as their relationships with siblings and caregivers, developing social networks, and exerting their agency through migration and other coping strategies, they remain vulnerable to trajectories of chronic poverty and social exclusion. The resilience, vulnerability and protective framework has been shown to be relevant in this study, particularly with regard to the emphasis on 'strengths' rather than a 'deficit' model, and recognising individuals' agency. However, the data also highlight some limitations with the concept of resilience, such as the tendency to individualise social problems, with less focus on the structural analysis of social inequalities and gender norms which impact on different members of the household. Thus, in this paper, the concept of resilience has been combined with gender analysis to give a more nuanced understanding of the processes of surviving and adapting to the HIV / AIDS epidemic for different individuals depending on their social location within the household and wider community.

The study therefore calls for a higher degree of recognition and support for the contribution that people living with HIV/ AIDS can make to society in terms of their rights to employment and livelihood strategies, the role they often play in caring for other people living with HIV/ AIDS and their potential involvement in communitybased education and prevention programmes. In particular, the research indicates the need to challenge gender norms and support men's involvement in caring for women, children and young people affected by HIV/ AIDS. Innovative development interventions are needed in providing for basic needs and in strengthening women, children and young people's resilience, particularly through their social networks and supporting their migration strategies. For example, to reduce the costs for carers of accepting orphans, effective social safety nets are needed to enable the most appropriate carers (who are often grandmothers) to care for foster children in adoptive households. This would enable children to stay with the relatives they feel closest to within the extended family, and be placed together with their siblings, which have

(C) Ruth Evans, 2005. Please cite as: Evans, R. (2005) 'Social networks, migration and care in Tanzania: caregivers' and children's resilience in coping with HIV/ AIDS', Journal of Children and Poverty, 11(2): 111-129. 
been shown to be important factors in supporting the successful migration of orphans within foster households and in enhancing the resilience of children in high stress family situations (Ansell \& Young, 2004; Gilligan, 2000). A broader concept of "social orphans" is needed, that is children whose parents are unable to provide for them, rather than just children orphaned by AIDS. Assistance should be targeted at all vulnerable children, based on this broader concept, and should aim to build their resilience within their families and communities in order to mitigate the impacts of the epidemic at the household level.

\section{Notes}

1. This paper is based on a presentation entitled, "Social Networks, Migration and Care in Tanzania: Supporting Women, Children and Young People's Resilience" prepared for the $2^{\text {nd }}$ African Conference on the Social Aspects of HIV / AIDS Research, International Convention Centre, Cape Town, 9-12 ${ }^{\text {th }}$ May 2004, organised by the Human Sciences Research Council, South Africa (see: www.sahara.org.za). 2. Based on findings from ethnographic research conducted with street children and children and families from AIDS-affected households in the Arusha region, northern Tanzania 2000-2002. The research was conducted in accordance with the ethical guidelines of the Social Research Association (see: www.the-sra.org.uk).

3. The names of all the research participants have been changed to protect their anonymity.

4. Translated from Swahili transcripts of tape-recorded semi-structured interviews as part of the fieldwork detailed in note 2 .

5. Elements of this data have been discussed in R. EVANS. 2002. Poverty, HIV, and Barriers to Education: Street Children's Experiences in Tanzania. Gender and Development, 10 (3): 51-62.

\section{References}

ANDERSON, J. \& L. DOYAL. 2004. Women from Africa living with HIV in London: a descriptive study. AIDS Care, 16 (1): 95-105.

ANSELL, N. \& L. YOUNG. 2004. Enabling Households to Support Successful Migration of AIDS Orphans in Southern Africa. AIDS Care, 16 (1): 3-10.

BARNETT, T. (1998) The epidemic in rural communities: the relevance of the African experience for India. In The Looming Epidemic: The Impact of HIV and AIDS in India, ed. by P. Godwin. London: Hurst and Company. pp.15070.

BARNETT, T. \& P. BLAIKIE. 1992. AIDS in Africa: its present and future impact. London: Belhaven.

BENDERA, S. 1999. Promoting Education for Girls in Tanzania. In Gender, Education and Development: Beyond access to empowerment, ed. by C. Heward and S. Bunwaree. London: Zed Books Ltd. pp.117-132.

BLOOM, M. 1996. Primary Prevention and Resilience: Changing Paradigms and Changing Lives. In Preventing Violence in America, ed. by P. Hampton, J. Jenkins and T. Gullotta. CA: Thousand Oaks.

BOLTON, P. \& C.M. WILK. 2004. How do Africans view the impact of HIV? A report from a Ugandan community. AIDS CARE, 16 (1), 123-128.

(C) Ruth Evans, 2005. Please cite as: Evans, R. (2005) 'Social networks, migration and care in Tanzania: caregivers' and children's resilience in coping with HIV/ AIDS', Journal of Children and Poverty, 11(2): 111-129. 
BOWLBY, J. 1988. Developmental psychiatry comes of age. American Journal of Psychiatry, 145(1): 1-10.

CALDWELL, J. 1997. The Impact of the African AIDS epidemic. Health Transition Review, 7 (2): 169-188.

EVANS, R.M.C. 2004a. Tanzanian Childhoods: Street Children's Narratives of Home. Journal of Contemporary African Studies, 22 (1): 69-92.

EVANS, R.M.C. 2004b. Negotiating Childhood: the Gendered Experiences of Street Children and Children in Difficult Circumstances in Tanzania. Ph.D. thesis, University of Hull.

EVANS, R. 2002. Poverty, HIV and barriers to education: street children's experiences in Tanzania. Gender and Development, 10(3): 51-62.

FOSTER, G., C. MAKUFA, R. DREW \& E. KRALOVEC. 1997. Factors leading to the establishment of child-headed households: The case of Zimbabwe. Health Transition Review, 7 (2), 155-168.

HOWARD, S., J. DRYDEN \& B. JOHNSON. 1999. Childhood Resilience: Review and Critique of Literature. Oxford Review of Education, 25 (3): 307-323.

GILLIGAN, R. 2001. Promoting Resilience. London: BAAF.

GILLIGAN, R. 2000. Adversity, Resilience and Young People: the Protective Value of Positive School and Spare Time Experiences. Children and Society, 14: 3747.

GILLIGAN, R. 1997. Beyond Permanence? The Importance of Resilience in Child Placement Practice and Planning. Adoption and Fostering, 21 (1):12-21.

GODWIN, P. 1998. Another social development crisis? In The Looming Epidemic: The Impact of HIV and AIDS in India, ed. by P. Godwin. pp.1-9.

GRAINGER, C., D. WEBB, \& L. ELLIOTT. 2001. Children Affected by HIV/ AIDS: Rights and Responses in the developing world. London: Save the Children.

HOWARD, S., J. DRYDEN, \& B. JOHNSON. 1999. Childhood Resilience: review and critique of literature. Oxford Review of Education, 25 (3): 307-323.

KARLENZA, X.M. 1998. Confronting the social consequences of AIDS. Child and Youth Care, 16(10):4-6.

KATEREGGA, C.N. 1999. Community-based Initiatives for Orphans and Abandoned Children: Strategies and Actions. Dar es Salaam: UNICEF.

KULEANA CENTER FOR CHILDREN'S RIGHTS. 1999. The State of Education in Tanzania - Crisis and Opportunity. Mwanza: Kuleana.

LOCKWOOD, M. 1997. Reproduction and Poverty in Sub-Saharan Africa. Tactics and Trade-Offs: Revisiting the links between gender and poverty, IDS Bulletin, 28 (3): 91-100.

LUTHAR, S. 1993. Annotation: Methodological and Conceptual Issues in Research on Childhood Resilience. Journal of Child Psychology and Psychiatry, 34(4): 441-454.

MASTEN \& COATSWORTH. 1998. 'The development of competence in favourable and unfavourable environments. Lessons from research on successful children'. American Psychologist. 53(2): 121-135.

MASTEN, A., K. BEST \& N. GARMEZY. 1990. Resilience and development: Contributions from the study of children who overcome adversity. Development and Psychopathology, 2 (1990): 425-444.

MHALU, F. \& H. LUPOGO. 2002 Welcome Statement, $2^{\text {nd }}$ National Multisectoral AIDS conference in Tanzania, Arusha, December 2002.

MINISTRY OF HEALTH. 2001. HIV/ AIDS/ STI Surveillance Report. Dar es Salaam: National AIDS Control Programme.

(C) Ruth Evans, 2005. Please cite as: Evans, R. (2005) 'Social networks, migration and care in Tanzania: caregivers' and children's resilience in coping with HIV/ AIDS', Journal of Children and Poverty, 11(2): 111-129. 
PANTER-BRICK, C. 2004. Homelessness, Poverty, and Risks to Health: Beyond at Risk Categorizations of Street Children. Children" s Geographies, 2(1).

PANTER-BRICK, C. 2002. Street Children, Human Rights and Public Health: a Critique and Future Directions. Annual Review Anthropology, 31: 147-171.

PRYOR, J. 2004. Stepfamilies and Resilience. Final Report. New Zealand: Centre for Social Research and Evaluation, Ministry of Social Development.

RUTTER, M. 1999. Resilience concepts and findings: implications for family therapy. Journal of Family Therapy, 21: 119-144.

RUTTER, M. 1990. Psychosocial resilience and protective mechanisms. In Risk and Protective Factors in the development of Psychopathology, ed. by J. Rolf, A. Masten, D. Chicchetti, K. Neuchterlein \& S. Weintraub. New York: Cambridge University Press. (pp.181-214)

RUTTER, M. 1985. Resilience in the Face of Adversity: Protective Factors and Resistance to Psychiatric Disorder. British Journal of Psychiatry, 147: 598611.

SCHOON, I. \& S. PARSONS. 2002. Competence in the Face of Adversity: the Influence of Early Family Environment and Long-term Consequences. Children and Society, 16: 260-272.

UNICEF. 2001. Situation Analysis of Children in Tanzania, Dar es Salaam, UNICEF

UNICEF. 1999 ${ }^{\mathrm{a}}$. Children in Need of Special Protection Measures: a Tanzanian case study. Dar es Salaam: UNICEF.

UNICEF. 1999 ${ }^{\mathrm{b}}$. Children Orphaned by AIDS: Frontline Responses from Eastern and Southern Africa, UNICEF \& UNAIDS, www.unicef.org (accessed August 2003).

URASSA, M., J. NGWESHEMI, R. ISINGO, Y. KUMOGOLA, \& J. BOERMA. 1997. Orphanhood, child fostering and the AIDS epidemic in rural Tanzania. In The Socio-demographic Impact of AIDS in Africa Conference. South Africa, February.

WALSH, F. 2002. 'A family resilience framework: innovative practice applications'. Family Relations. 51(2):130-137.

WOODHEAD, M., R. BURR \& H. MONTGOMERY. 2003 Adversities and Resilience. In Changing Childhoods local and global, ed. by H.Montgomery, R. Burr and M. Woodhead. The Open University: Milton Keynes / John Wiley and Sons Ltd.: Chichester. (pp.1-44)

YOUNG, L. \& N. ANSELL. 2003. Fluid Households, Complex Families: The Impacts of Children's Migration as a Response to HIV/ AIDS in Southern Africa. The Professional Geographer, 55 (4): 464-476.

\section{Author biography}

Ruth Evans completed her doctoral thesis into the gendered experiences of street children and other children in difficult circumstances in Tanzania, based on childfocused ethnographic research. She has worked as a Research Associate with young people in the UK for the Social Policy and Gender Studies departments at the University of Hull. She is currently working as a Research Fellow at the Institute of Applied Social Studies, University of Birmingham. Contact: R.M.Evans@bham.ac.uk

(C) Ruth Evans, 2005. Please cite as: Evans, R. (2005) 'Social networks, migration and care in Tanzania: caregivers' and children's resilience in coping with HIV/ AIDS', Journal of Children and Poverty, 11(2): 111-129. 